\title{
Quality of individual and group level interventions for first-episode psychosis at the tertiary psychiatric hospital in Uganda
}

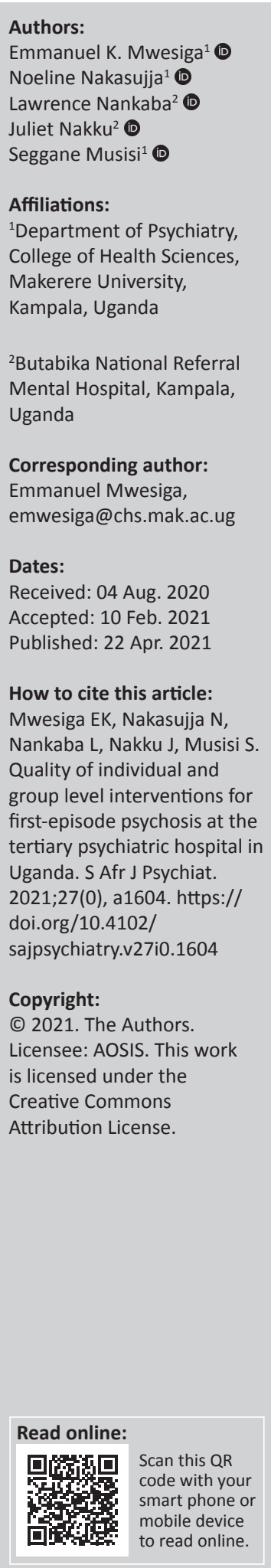

Background: Individual and group level interventions have the largest effect on outcomes in patients with the first episode of psychosis. The quality of these individual and group level interventions provided to first-episode psychosis patients in Uganda is unclear.

Aim: To determine the quality of the individual and group level interventions provided to first episode psychosis patients in Uganda

Setting: The study was performed at the only tertiary psychiatric hospital in Uganda.

Methods: A retrospective chart review of recently discharged adult in-patients with the first episode of psychosis was performed. The proportion of participants who received different essential components for individual and group level interventions were calculated. From the different proportions, the quality of the services across the individual and group interventions was determined using the first-episode psychosis services fidelity scale (FEPS-FS). The FEPSFS assigns a grade of 1-5 on a Likert scale depending on the proportion of patients who received the different components of the intervention. Twelve essential components across the individual and group interventions were assessed and their quality quantified.

Results: The final sample included 156 first-episode psychosis patients. The median age was 27 years (inter-quartile range [IQR] [24-36]) and 55\% of the participants were female. All 12 essential components had poor quality with the range of scores on the FEPS-FS between one and three. Only one essential component assessed (use of single antipsychotics) had moderate quality.

Conclusion: Amongst current services at the Butabika National Referral Mental Hospital in Uganda, the essential components for individual and group level interventions for psychotic disorders are of poor quality. Further studies are required on how the quality of these interventions can be improved.

Keywords: early intervention services; low and middle income country; public health; service provision; first episode psychosis; individual level interventions; group level interventions.

\section{Introduction}

Psychotic disorders that include schizophrenia spectrum and bipolar disorders, if left untreated are associated with poor physical, psychological, social and occupational outcomes. ${ }^{1,2,3,4}$ Psychotic disorders follow an often common course of a premorbid phase, the prodrome, first-episode psychosis, a chronic relapsing phase and finally social impairment. ${ }^{5}$ Current treatment guidelines recommend for the early management of psychotic disorders at the first episode of psychosis. ${ }^{6,7}$ Early management, at the first episode of psychosis, has been associated with greater cognitive functioning, improved social functioning, fewer relapses and improved quality of life. ${ }^{6,8}$ Often early management for psychotic disorders is provided through specialised early intervention services (SEIS) which provide various interventions to ensure improved outcomes. ${ }^{9,10}$

In their seminal paper, Addington et al. described six key interventions that must be provided to patients with a first episode of psychosis to ensure improved patient outcomes. ${ }^{11}$ These interventions often provided in SEIS for psychotic disorders included; (1) population-level intervention and access; (2) comprehensive assessments and care plan; (3) individual-level interventions; (4) group-level interventions; (5) service system and models of intervention, and (6) evaluation and quality improvement. ${ }^{11,12}$ Within each intervention were essential components that varied in their effectiveness in improving patient outcomes. ${ }^{11}$ Addington et al. thus defined a grading system for the effectiveness of different essential components on patient outcomes. ${ }^{11}$ 
Grade 'A' implied there was strong evidence to support the component on improving patient outcomes. Grade ' $\mathrm{B}$ ' implied there was supportive evidence of the component on improving patient outcomes. Grade ' $\mathrm{C}$ ' implied this was just an opinion of clinicians on the effect of the component improving patient outcomes. Grade ' $\mathrm{D}$ ' implied there was no evidence of benefit or harm of a component improving patient outcomes. ${ }^{11,13}$ An adaptation of their original 31 components, as well as the effectiveness of each component in improving outcomes, are highlighted in Table 1 below.

TABLE 1: Description and strength of essential components for early intervention services.

\begin{tabular}{|c|c|}
\hline Intervention and essential components & $\begin{array}{l}\text { Effectiveness of component in } \\
\text { improving patient outcomes }\end{array}$ \\
\hline \multicolumn{2}{|l|}{ Population-level intervention and access } \\
\hline Targeted public education & B \\
\hline $\begin{array}{l}\text { Targeted education for health and social service } \\
\text { providers }\end{array}$ & B \\
\hline $\begin{array}{l}\text { Acceptance of referrals with potential comorbid } \\
\text { substance use disorders }\end{array}$ & C \\
\hline $\begin{array}{l}\text { Communication protocol between inpatient units } \\
\text { and first-episode psychosis services }\end{array}$ & $\mathrm{D}$ \\
\hline Timely contact with referred individual & $\mathrm{D}$ \\
\hline \multicolumn{2}{|l|}{ Comprehensive assessments and care plan } \\
\hline Individual-centred assessments & $\mathrm{C}$ \\
\hline Comprehensive assessment upon enrolment & $\mathrm{C}$ \\
\hline Assessment of suicidal thinking and behaviour & B \\
\hline Care plan addresses psychosocial needs & $\mathrm{C}$ \\
\hline Informed decision-making & C \\
\hline Informed consent & $\mathrm{D}$ \\
\hline \multicolumn{2}{|l|}{ Individual-level interventions } \\
\hline \multicolumn{2}{|l|}{ Pharmacotherapy } \\
\hline Selection of antipsychotic medication & A \\
\hline Mode of antipsychotic administration & C \\
\hline Low-dose, slow-increment antipsychotic medication & A \\
\hline Clozapine for treatment resistance & A \\
\hline Use of single antipsychotics & A \\
\hline Monitoring metabolic changes & B \\
\hline Monitoring antipsychotic medication side effects & C \\
\hline $\begin{array}{l}\text { Proactive steps to prevent weight gain and metabolic } \\
\text { effects }\end{array}$ & B \\
\hline \multicolumn{2}{|l|}{ Psychoeducation, Individual } \\
\hline Individual psychoeducation & B \\
\hline \multicolumn{2}{|l|}{ Addictions treatment } \\
\hline Integrated mental health and addictions treatment & C \\
\hline \multicolumn{2}{|l|}{ Vocational and educational plans } \\
\hline Vocational plan & C \\
\hline Supported employment & A \\
\hline \multicolumn{2}{|l|}{ Group-level interventions } \\
\hline Multifamily group psychoeducation & A \\
\hline Group family psychoeducation & B \\
\hline \multicolumn{2}{|l|}{ Service systems and models of intervention } \\
\hline Psychiatrist as part of the team & C \\
\hline Duration of first-episode psychosis services & B \\
\hline $\begin{array}{l}\text { Supervision and education of first-episode psychosis } \\
\text { services staff }\end{array}$ & $\mathrm{C}$ \\
\hline Weekly team meetings & B \\
\hline Active outreach services & C \\
\hline Crisis intervention services & C \\
\hline \multicolumn{2}{|l|}{ Evaluation and quality improvement } \\
\hline Tracking of process and outcome measures & $\mathrm{C}$ \\
\hline
\end{tabular}

Individual and group level interventions are the most effective interventions for patients with first-episode psychosis. ${ }^{12,14}$ They are the only interventions with essential components that have an effectiveness grade of ' $\mathrm{A}$ ' (there is strong evidence of the essential components' effect on patient outcomes). ${ }^{11}$

Individual-level interventions have 12 components and 5 of them (selection of antipsychotic medication, supported employment, use of single antipsychotics, low dose slow increment for antipsychotic medication, clozapine for treatment resistance) have an effectiveness grade of ' $A$ '. ${ }^{6,15,16}$ Group-level interventions have only two components: one (multifamily group psychoeducation) is graded ' $\mathrm{A}$ ' for effectiveness on outcomes, whilst the other (group family psychoeducation) is rated ' $B$ ' (supportive evidence) for effectiveness on outcomes for patients with psychotic disorders. ${ }^{17,18}$

We aimed to determine the quality of individual and group level interventions provided to patients with a first episode of psychosis at Butabika National Referral Mental Hospital in Uganda, also known as Butabika Hospital. Even though there are no SEIS for psychotic disorders at the hospital, we hypothesised that individual and group level interventions of SEIS for psychotic disorders are provided within routine care. It is however unclear if the individual and group level interventions provided are of the prerequisite quality. Given that the largest mental illness burden in this setting is for psychotic disorders, ${ }^{19}$ the interventions that have the biggest impact on patient outcomes must be provided with the utmost quality.

\section{Method \\ Study design and setting}

This was a retrospective chart review performed at Butabika National Referral Mental Hospital in Uganda. It is the only national psychiatric hospital in Uganda. It is also responsible for directing mental health policy and financing, issuing directives on which interventions are to become standard care in the country.

There are specialised clinics for addiction, child and adolescent mental health, occupational therapy and human immunodeficiency virus/acquired immunodeficiency syndrome (HIV/AIDS) mental health. Although psychotic disorders are the most common disorders at Butabika Hospital, ${ }^{19}$ there are currently no SEIS for psychotic disorders.

\section{Study participants}

Participants were recruited from a larger study on predictors of cognitive impairment amongst patients with the first episode of psychosis. The participants were all antipsychotic naïve at enrollment, aged 18-60 years, without substance use history, HIV / AIDS and/or syphilis. This retrospective chart review included all participants enrolled in the initial study. 


\section{Tools}

\section{The first-episode psychosis services fidelity scale}

The quality of the services provided for each component of the specialised service was assessed using the FirstEpisode Psychosis Services Fidelity Scale (FEPS-FS) ${ }^{20}$ This is an evidence-based practice and rating criteria used to assess the degree to which programmes deliver evidencebased practices. ${ }^{21}$ The tool assesses the extent to which a service in its entirety is providing evidence-based interventions. It does not assess how many participants are receiving the service but rather the overall standard of care being provided.

A Likert scale from 1 to 5 determines how well the standard of care is with a score of 1 if the target component is met in $0 \%-19 \%$ of patients, 2 in $20 \%-39 \%$ of patients, 3 in $40 \%-59 \%$ of patients, 4 in $60 \%-79 \%$ of patients and 5 if the target component is met in greater than $80 \%$ of patients. Ratings of four and above imply satisfactory performance. ${ }^{21}$

\section{Study procedure}

A master list of all the patients previously enrolled was made, and the files of the participants were obtained from the hospital records office. Files were reviewed from the period of the participant's first admission. The different essential components of individual and group level interventions received by each participant were recorded till discharge. This data was captured in a spreadsheet specifically designed to assess the interventions and essential components that were available. For each essential component assessed, a 'yes'/'no' was recorded in the excel sheet depending on whether the participant had or had not received the essential component. If the research assistant could not tell if the essential component had been provided to the participant, the research assistant reported 'unclear'. A summary excel sheet can be found in the supplementary files. The specific criteria to determine if an essential component had been received are highlighted is provided in Table 2. The questions used to determine if a component was available were developed from the literature on essential components by Addington. ${ }^{11}$ Research assistants were psychiatric clinical officers trained before the onset of the study on how to assess for the different criteria in Addington's checklist from the patient file.

\section{Statistical analyses}

The information abstracted from the chart review was merged by study identification numbers to the original dataset on predictors of cognitive impairment amongst patients with the first episode of psychosis. Data was analysed using Stata version 14.0.22 Descriptive statistics were employed to determine the proportion of patients receiving each essential component. The proportions of patients receiving a specific essential component were then used to determine the quality of the essential component provided.
TABLE 2: Summary of how the essential, evidence-based components for specialised early intervention services were assessed in the study.

\begin{tabular}{|c|c|}
\hline Component & Description in the study \\
\hline \multicolumn{2}{|l|}{ Individual-level interventions } \\
\hline \multicolumn{2}{|l|}{ Pharmacotherapy } \\
\hline Selection of antipsychotic medication & $\begin{array}{l}\text { FGA versus SGA. Second-generation } \\
\text { antipsychotics preferred. }\end{array}$ \\
\hline Mode of antipsychotic administration & $\begin{array}{l}\text { Oral, parental or both. Oral preferred } \\
\text { initially with the depot in the long term. }\end{array}$ \\
\hline $\begin{array}{l}\text { Low-dose, slow-increment antipsychotic } \\
\text { medication }\end{array}$ & $\begin{array}{l}\text { Assessed whether a low dose of any } \\
\text { antipsychotic was started with } \\
\text { subsequent increments were necessary. }\end{array}$ \\
\hline Clozapine for treatment resistance & $\begin{array}{l}\text { Not applicable as this was a first episode } \\
\text { population. }\end{array}$ \\
\hline Use of single antipsychotics & Used one or multiple antipsychotics. \\
\hline Monitoring metabolic changes & BMI, cholesterol, RBS, weight gain. \\
\hline $\begin{array}{l}\text { Monitoring antipsychotic medication } \\
\text { side effects }\end{array}$ & Notes reporting side effects. \\
\hline $\begin{array}{l}\text { Proactive steps to prevent weight gain } \\
\text { and metabolic effects }\end{array}$ & Recommended exercise in notes. \\
\hline \multicolumn{2}{|l|}{ Psychoeducation, individual } \\
\hline Individual psychoeducation & Clinical psychologist review. \\
\hline \multicolumn{2}{|l|}{ Addictions treatment } \\
\hline $\begin{array}{l}\text { Integrated mental health and } \\
\text { addictions treatment }\end{array}$ & $\begin{array}{l}\text { Not assessed, as substance use } \\
\text { disorder was an exclusion criterion in } \\
\text { the previous study. }\end{array}$ \\
\hline \multicolumn{2}{|l|}{ Vocational and educational plans } \\
\hline Vocational plan & Social worker review. \\
\hline Supported employment & Plan for supported employment. \\
\hline \multicolumn{2}{|l|}{ Group-level interventions } \\
\hline Multifamily group psychoeducation & $\begin{array}{l}\text { Meetings with families who were taught } \\
\text { about the illness. }\end{array}$ \\
\hline Group family psychoeducation & Family sessions. \\
\hline \multicolumn{2}{|c|}{$\begin{array}{l}\text { Source: Developed from the literature on essential components by Addington DE, McKenzie } \\
\text { E, Norman R, Wang J, Bond GR. Essential evidence-based components of first-episode } \\
\text { psychosis services. Psychiatr Serv. 2013;64(5):452-457. https://doi.org/10.1176/appi. } \\
\text { ps.201200156 }\end{array}$} \\
\hline \multicolumn{2}{|c|}{$\begin{array}{l}\text { FGA, first-generation antipsychotics; SGA, second-generation antipsychotics; BMI, body } \\
\text { mass index; RBS, random blood sugar. }\end{array}$} \\
\hline
\end{tabular}

\section{Ethical considerations}

As this was a retrospective chart review of file records, we did not receive individual patient consent. In the primary study, participants were asked if they could be contacted for enrolment in future studies. This chart review received institutional approval from the hospital administration. The original study from which the patients were recruited received ethical approval from the Uganda National Council for Science and Technology (UNCST), the School of Medicine Research and Ethics Committee (SOMREC) of Makerere University, ethical clearance reference number: 2017-086, and institutional approval from Butabika National Referral Mental Hospital.

\section{Results}

The charts of 156 participants were reviewed. Participants had been enrolled in the previous study between January 2018 and January 2019. The median age of the participants was 27 years (IQR 24-36). Most (84/156 [55.3\%]) of the participants were female. The majority $(83.6 \%)$ of participants were either unemployed or in non-formal employment. Most (69\%) of participants reported that this was their first time of experiencing symptoms and $40 \%$ had consulted an alternative and complementary therapist (traditional healer, religious healer) before admission at the hospital. Other characteristics of the patients are highlighted in Table 3 below. 
TABLE 3: Baseline characteristics of the participants.

\begin{tabular}{|c|c|c|c|c|c|}
\hline \multirow[t]{2}{*}{ Factor } & \multirow[t]{2}{*}{ Level } & \multicolumn{2}{|c|}{ Frequency } & \multirow[t]{2}{*}{ Median } & \multirow[t]{2}{*}{ IQR } \\
\hline & & $n$ & $\%$ & & \\
\hline Age & Median & - & - & 27 & $24-36$ \\
\hline \multirow[t]{2}{*}{ Gender } & Male & 68 & 44.7 & - & - \\
\hline & Female & 84 & 55.3 & - & \\
\hline \multirow[t]{3}{*}{ Marital status } & Single & 76 & 50.0 & - & - \\
\hline & Married & 47 & 30.9 & - & - \\
\hline & Divorced & 29 & 19.1 & - & - \\
\hline \multirow{4}{*}{$\begin{array}{l}\text { Current employment } \\
\text { history }\end{array}$} & Student & 12 & 7.9 & - & - \\
\hline & Formal employment & 13 & 8.6 & - & - \\
\hline & Non-formal employment & 63 & 41.5 & - & - \\
\hline & Unemployed & 64 & 42.1 & - & - \\
\hline \multirow{5}{*}{$\begin{array}{l}\text { Highest level of } \\
\text { education }\end{array}$} & No school & 4 & 2.6 & - & - \\
\hline & Primary & 62 & 40.8 & - & - \\
\hline & Secondary & 65 & 42.8 & - & - \\
\hline & Diploma & 17 & 11.2 & - & - \\
\hline & University & 4 & 2.6 & - & - \\
\hline \multirow[t]{5}{*}{ Ethnic } & Bantu & 120 & 80.0 & - & - \\
\hline & Nilotic & 10 & 6.7 & - & - \\
\hline & NiloHamites & 5 & 3.3 & - & - \\
\hline & Sudanic & 5 & 3.3 & - & - \\
\hline & Hamites & 10 & 6.7 & - & - \\
\hline \multirow[t]{2}{*}{ Diagnosis } & Affective psychosis & 53 & 49.1 & - & - \\
\hline & Non-affective psychosis & 55 & 50.9 & - & - \\
\hline $\begin{array}{l}\text { Age first seeking help } \\
\text { for psychosis }\end{array}$ & Median & - & - & 25 & $21-29$ \\
\hline \multirow{2}{*}{$\begin{array}{l}\text { First presentation at } \\
\text { the medical facility }\end{array}$} & No & 12.7 & 12.7 & - & - \\
\hline & Yes & 87.3 & 87.3 & - & - \\
\hline \multirow{2}{*}{$\begin{array}{l}\text { Previous use of } \\
\text { alternative therapy }\end{array}$} & No & 35.1 & 35.1 & - & - \\
\hline & Yes & 64.9 & 64.9 & - & - \\
\hline
\end{tabular}

$I Q R$, inter-quartile range.

Most service components were of poor quality as the proportion of patients receiving the component was few. The proportions of patients who received different individual and group level interventions as well as the quality of the services for each component are highlighted in Table 4 below.

\section{Discussion}

In confirming our hypothesis, we found that Butabika National Referral Mental Hospital in Uganda already provides individual and group level interventions for patients with the first episode of psychosis. The quality of essential components is however poor.

Of the six interventions that had been given an ' $\mathrm{A}$ ' rating in the Addington checklist (selection of antipsychotic medication, supported employment, use of single antipsychotics, low dose slow increment for antipsychotic medication, clozapine for treatment resistance and multifamily group psychoeducation), only one (use of single antipsychotics) reached the level of moderate quality service provision in this setting. The proportion of patients who used only one antipsychotic was similar to literature from high-income countries (HIC) ${ }^{23,24}$ Whether this was by design or because of a limited selection of antipsychotic drugs is not clear from the study. Mental health services in low resource settings are often plagued by minimal financing which might point to limited drug selection..$^{25,26}$ In Uganda, for example, there is limited availability of second-generation antipsychotics (SGA). ${ }^{27}$

Three other interventions with ' $\mathrm{A}$ ' rating (selection of antipsychotic medication, supported employment, low dose slow increment for antipsychotic medication) were of poor quality. The poor quality in the component of slow dose increment of antipsychotic medication could be because of various factors. First, we are cognisant of the fact that initial doses for initiation of treatment are dependent on the severity of the illness. ${ }^{28}$ In our setting, Abbo et al. highlighted that patients with psychotic disorders often present late with severe illness after attempting alternative treatments. ${ }^{29,30,31,32}$ There might therefore be a need to initiate treatment at higher doses than is recommended. Second, it might also not be possible to make slow increments because of the lack of formulations of antipsychotic medications available in low resource settings. ${ }^{27}$ Finally, given the brief time frame of the study (admission to discharge), it is possible that the increments were made over a longer period. This study, therefore, needs replication by longitudinal studies to clearly define the dose adjustments over 2 years.

Selection of antipsychotic medication had most participants receiving first-generation antipsychotics (FGAs) which are cheaper even though SGA are preferred. ${ }^{27}$ This is like literature from low resource settings whilst HIC often use SGA. These FGAs are associated with a greater side effect profile leading to poor drug adherence. Multifamily group psychoeducation and supported employment have also been shown to have strong evidence of good outcomes for patients with psychotic disorders. These services are unfortunately still of poor quality at Butabika hospital as there are a limited number of therapists employed by the hospital. ${ }^{19}$ This may be because of human resource and financing limitations which are common in low resource settings like Uganda. ${ }^{26,33,34,35}$ The lack of patients being supported in employment is because of the general lack of social support services in Uganda. These supported employment programmes also require extensive resources and personnel that are not available in low resource settings like Uganda. ${ }^{36,37}$

Four interventions were rated as having supportive evidence (rating B) for improved outcomes by Addington et al. ${ }^{11}$ These included monitoring of metabolic side effects, individual psychoeducation, group psychoeducation and proactive steps to promote exercise and prevent weight gain. That there was moderate quality of the individual psychoeducation intervention is noteworthy. This is because SEIS for psychotic disorders not only target first-episode psychosis patients but also those in the psychosis prodrome, as well as high-risk and ultra-high risk individuals. ${ }^{6}$ This psychoeducation is therefore a tool that can be used in the prevention of the psychosis onset, or early initiation of treatment. The available services were of poor quality for monitoring side effects and preventing weight gain. There is a need for improved awareness of the increased risk for non-communicable diseases in patients with psychotic disorders, even in patients 
TABLE 4: Quality of essential components for individual and group level interventions.

\begin{tabular}{|c|c|c|c|c|}
\hline \multirow[t]{2}{*}{ Essential component } & \multirow{2}{*}{$\begin{array}{c}\text { Effectiveness of } \\
\text { component in improving } \\
\text { patient outcomes }\end{array}$} & \multicolumn{2}{|c|}{$\begin{array}{l}\text { Proportion of participants who had received } \\
\text { the component }\end{array}$} & \multirow{2}{*}{$\begin{array}{l}\text { Quality of service as } \\
\text { assessed by FEPS-FS } \\
\text { Range (1-5) }\end{array}$} \\
\hline & & $N$ & $\%$ & \\
\hline \multicolumn{5}{|l|}{ Individual-level interventions } \\
\hline \multicolumn{5}{|l|}{ Pharmacotherapy } \\
\hline \multirow[t]{3}{*}{ Selection of antipsychotic medication } & A & Both 27 & 16.98 & 01 \\
\hline & & FGA 129 & 81.13 & \\
\hline & & SGA 03 & 1.89 & \\
\hline \multirow[t]{3}{*}{ Mode of antipsychotic administration } & C & Oral 52 & 32.70 & 02 \\
\hline & & Parenteral 01 & 0.63 & \\
\hline & & Both 106 & 66.67 & \\
\hline \multirow{3}{*}{$\begin{array}{l}\text { Low-dose, slow-increment antipsychotic } \\
\text { medication }\end{array}$} & A & Yes 05 & 3.14 & 01 \\
\hline & & No 152 & 95.60 & \\
\hline & & Unclear 02 & 1.26 & \\
\hline Clozapine for treatment resistance & A & N/A & - & N/A \\
\hline Use of single antipsychotics & & No 79 & 50.32 & \\
\hline \multirow[t]{2}{*}{ Monitoring metabolic changes } & B & Yes 04 & 2.5 & 01 \\
\hline & & No 156 & 97.5 & \\
\hline \multirow[t]{2}{*}{ Monitoring antipsychotic medication side effects } & $\mathrm{C}$ & Yes 39 & 24.68 & 02 \\
\hline & & No 119 & 75.32 & \\
\hline \multirow{4}{*}{$\begin{array}{l}\text { Proactive steps to prevent weight gain and } \\
\text { metabolic effects }\end{array}$} & B & Yes 02 & 1.26 & 01 \\
\hline & & (Diet $=01)$ & & \\
\hline & & $($ Exercise $=01)$ & & \\
\hline & & No 157 & 98.74 & \\
\hline \multicolumn{5}{|l|}{ Psychoeducation, Individual } \\
\hline \multirow[t]{2}{*}{ Individual psychoeducation } & B & Yes 36 & 22.78 & 02 \\
\hline & & No 122 & 77.22 & \\
\hline \multicolumn{5}{|l|}{ Addictions treatment } \\
\hline Integrated mental health and addictions treatment & C & N/A & - & N/A \\
\hline \multicolumn{5}{|l|}{ Vocational and educational plans } \\
\hline \multirow[t]{2}{*}{ Supported employment } & A & Yes 01 & 0.63 & 01 \\
\hline & & No 157 & 99.37 & \\
\hline \multicolumn{5}{|l|}{ Group-level interventions } \\
\hline \multirow[t]{2}{*}{ Multifamily group psychoeducation } & A & Yes 22 & 13.92 & 01 \\
\hline & & No 136 & 86.08 & \\
\hline \multirow[t]{2}{*}{ Group family psychoeducation } & B & Yes 21 & 13.29 & 01 \\
\hline & & No 137 & 86.71 & \\
\hline
\end{tabular}

FGA, first-generation antipsychotics; SGA, second-generation antipsychotics; FEPS-FS, first-episode psychosis services fidelity scale; N/A, not applicable; A, strong evidence; B, supportive evidence; C, opinion.

on first-generation antipsychotic medication. ${ }^{38}$ Increased promotion of exercise will be required as the hospital adapts SGA as the mainstay of treatment. ${ }^{27}$

The level of evidence for a vocational plan, mode of administration of antipsychotics and monitoring side effects was ' $C$ ' (opinion). All these interventions had poor to moderate quality of services in the hospital. In low resource settings like Uganda FGA are more available than SGA, FGA. $^{27}$ These FGAs are often associated with worse side effects leading to poorer adherence and worse outcomes. ${ }^{39,40}$ We postulate that in low resource settings monitoring antipsychotic side effects may have a larger impact on the outcome than in HIC. ${ }^{39}$

\section{Study limitations}

There have been many previous attempts to identify services essential for first-episode psychosis clinics. ${ }^{11,16}$
However, the Delphi processes and systematic reviews that identified these core components had limited representation from low- and middle-income countries. As such many of these processes may not be culturally specific, hence calling for pre-implementation cultural validation of the exercise. For example, given that many of the participants were unemployed or in non-formal employment, it is possible that vocational plans have a bigger impact on outcomes and therefore may need to be assigned higher levels of evidence in our setting. The same argument made for integrated addictions treatment has given the high rates of substance abuse in our setting, not just amongst patients with psychotic disorders but the general population as well. ${ }^{41,42}$ Further research is therefore needed to validate the low levels of evidence (opinion) for these interventions in low resource settings. This study however may form a basis for the development of SEIS for psychotic disorders in the region. 


\section{Conclusions and recommendations}

Our findings, in this study, showed that even within the everyday care in our low resource settings, there are essential components of SEIS for psychotic disorders that are available that could be implemented at Butabika National Referral Mental Hospital. There is a need however, for improvement in the quality of these services, especially in those components that showed the strongest evidence for improved outcomes in previous studies. Finally, long-term studies are needed to validate the level of evidence for these components given the human resource, financing and health-seeking behaviour differences between high-income and low-income countries, and in different cultural settings. Further research is also needed on the availability of other components like population-level interventions which are necessary for developing SEIS for psychotic disorders. ${ }^{43}$

\section{Acknowledgements}

We are grateful to Miss Anne Nanyonga of the Records Office at Butabika National Referral Mental Hospital who assisted in organising the patient chart files.

\section{Competing interests}

The authors declare that they have no financial or personal relationships that may have inappropriately influenced them in writing this article.

\section{Authors' contributions}

E.K.M., N.N. and S.M. conceptualised the research idea. E.K.M., L.N. and J.N. supervised the data extraction exercise. E.K.M., N.N. and S.M. advised on the analysis of the results. All authors were involved in writing the manuscript and approved the final manuscript for submission.

\section{Funding information}

The work was supported by Grant Number D43TW010132 supported by Office of the Director, National Institutes of Health (OD), National Institute of Dental \& Craniofacial Research (NIDCR), National Institute of Neurological Disorders and Stroke (NINDS), National Heart, Lung and Blood Institute (NHLBI), Fogarty International Centre (FIC), National Institute on Minority Health and Health Disparities (NIMHD).

\section{Data availability}

The minimal anonymised data set necessary to replicate our study findings can be found at https:/ / data.mendeley.com/ datasets/4tgf7trmnz/1.

\section{Disclaimer}

The views and opinions expressed in this article are those of the authors and do not necessarily reflect the official policy or position of any affiliated agency of the authors.

\section{References}

1. Gaebel W, Zielasek J. Focus on psychosis. Dialogues Clin Neurosci. 2015;17(1) 9-18. https://doi.org/10.31887/DCNS.2015.17.1/wgaebel

2. Whiteford HA, Degenhardt L, Rehm J, et al. Global burden of disease attributable to mental and substance use disorders: Findings from the global burden of disease study 2010. Lancet. 2013;382(9904):1575-1586. https://doi.org/10.1016/S01406736(13)61611-6

3. Vigo D, Thornicroft G, Atun R. Estimating the true global burden of mental illness. Lancet Psychiatry. 2016;3(2):171-178. https://doi.org/10.1016/S2215 0366(15)00505-2

4. Rössler W, Salize HJ, Van Os J, Riecher-Rössler A. Size of burden of schizophrenia and psychotic disorders. Eur Neuropsychopharmacol. 2005;15(4):399-409. https://doi.org/10.1016/j.euroneuro.2005.04.009

5. Dutta R, Greene T, Addington J, McKenzie K, Phillips M, Murray RM. Biological, life course, and cross-cultural studies all point toward the value of dimensional and developmental ratings in the classification of psychosis. Schizophr Bull. 2007; 33(4):868-876. https://doi.org/10.1093/schbul/sbm059

6. Marshall M, Rathbone J. Early intervention for psychosis. Cochrane Database Syst Rev. 2011;15(6):CD004718. https://doi.org/10.1002/14651858.CD004718.pub3

7. Breitborde NJK, Srihari VH, Woods SW. Review of the operational definition for first-episode psychosiseip. Early Interv Psychiatry. 2009;3(4):259-265. https://doi. org/10.1111/j.1751-7893.2009.00148.x

8. Santesteban-Echarri O, Paino $M$, Rice $S$, et al. Predictors of functional recovery in first-episode psychosis: A systematic review and meta-analysis of longitudinal studies. Clin Psychol Rev. 2017;58:59-75. https://doi.org/10.1016/j.cpr.2017.09.007

9. Breitborde NJ, Moe AM, Ered A, Ellman LM, Bell EK. Optimizing psychosocial interventions in first-episode psychosis: Current perspectives and future interventions in first-episode psychosis: Current perspectives and future
directions. Psychol Res Behav Manag. 2017;10:119-128. https://doi.org/10.2147/ PRBM.S111593

10. Moe AM, Rubinstein EB, Gallagher CJ, Weiss DM, Stewart A, Breitborde NJ. Improving access to specialized care for first-episode psychosis: An ecological model. Risk Manag Healthc Policy. 2018;11:127-138. https://doi.org/10.2147/ RMHP.S131833

11. Addington DE, McKenzie E, Norman R, Wang J, Bond GR. Essential evidencebased components of first-episode psychosis services. Psychiatr Serv. 2013; 64(5):452-457. https://doi.org/10.1176/appi.ps.201200156

12. Kozloff N, Foussias G, Durbin J, et al. Early psychosis intervention-spreading evidence-based treatment (EPI-SET): Protocol for an effectiveness-implementation study of a structured model of care for psychosis in youth and emerging adults. BMJ Open. 2020;10(6):e034280.

13. White DA, Luther L, Bonfils KA, Salyers MP. Essential components of early intervention programs for psychosis: Available intervention services in the United States. Schizophr Res. 2015;168(1-2):79-83. https://doi.org/10.1016/j.schres.2015.08.020

14. Leung CC, Gadelrab R, Ntephe CU, McGuire PK, Demjaha A. Clinical course, neurobiology and therapeutic approaches to treatment resistant schizophrenia: Toward an integrated view. Front Psychiatry. 2019;10:601. https://doi.org/ 10.3389/fpsyt.2019.00601

15. Bertolote J, McGorry P. Early intervention and recovery for young people with early psychosis: Consensus statement. Br J Psychiatry. 2005;187(S48):s116-s119. https://doi.org/10.1192/bjp.187.48.s116

16. Marshall M, Lockwood A, Lewis S, Fiander M. Essential elements of an early intervention service for psychosis: The opinions of expert clinicians. BMC Psychiatry. 2004;4:17. https://doi.org/10.1186/1471-244X-4-17

17. Datta SS, Daruvala R, Kumar A. Psychological interventions for psychosis in adolescents. Cochrane Database Syst Rev. 2020;7:CD009533. https://doi.org/ 10.1002/14651858.CD009533.pub2

18. McFarlane WR. Family interventions for schizophrenia and the psychoses: A review. Family Process. 2016;55(3):460-482. https://doi.org/10.1111/famp.12235

19. Mwesiga EK, Nakasujja N, Nakku J, et al. One year prevalence of psychotic disorders among first treatment contact patients at the national psychiatric referral and teaching hospital in Uganda. PLoS One. 2020;15(1):e0218843. https://doi.org/10.1371/journal.pone.0218843

20. Addington DE, Norman R, Bond GR, et al. Development and testing of the firstepisode psychosis services fidelity scale. Psychiatr Serv. 2016;67(9):1023-1025. https://doi.org/10.1176/appi.ps.201500398

21. Durbin J, Selick A, Langill G, et al. Using fidelity measurement to assess quality of early psychosis intervention services in Ontario. Psychiatr Serv. 2019:70(9): 840-844. https://doi.org/10.1176/appi.ps.201800581

22. Stata M. Software version 14.0. College Station, TX: Stata Corp; 2018.

23. Morrison AP, Law $H$, Carter $L$, et al. Antipsychotic drugs versus cognitive behavioural therapy versus a combination of both in people with psychosis: A randomised controlled pilot and feasibility study. Lancet Psychiatry. 2018; 5(5):411-423. https://doi.org/10.1016/S2215-0366(18)30096-8

24. Werner FM, Covenas R. Long-term administration of antipsychotic drugs in schizophrenia and influence of substance and drug abuse on the disease outcome. Curr Drug Abuse Rev. 2017;10(1):19-24. https://doi.org/10.2174/187447371066 6171020104524

25. Semrau M, Evans-Lacko S, Alem A, et al. Strengthening mental health systems in low- and middle-income countries: The Emerald programme. BMC Med. 2015;13:79. https://doi.org/10.1186/s12916-015-0309-4

26. Ssebunnya J, Kangere S, Mugisha J, et al. Potential strategies for sustainably financing mental health care in Uganda. Int J Ment Health Syst. 2018;12:74. https://doi.org/10.1186/s13033-018-0252-9 
27. Lubinga SJ, Mutamba BB, Nganizi A, Babigumira JB. A cost-effectiveness analysis of antipsychotics for treatment of schizophrenia in Uganda. Appl Health Econ Health Pol. 2015;13(5):493-506. https://doi.org/10.1007/s40258-015-0176-3

28. Schatzberg AF, Nemeroff CB. The American psychiatric association publishing textbook of psychopharmacology. Washington, DC and London: American Psychiatric Pub; 2017.

29. Abbo C, Okello ES, Musisi S, Waako P, Ekblad S. Naturalistic outcome of treatment of psychosis by traditional healers in Jinja and Iganga districts, Eastern Uganda - A 3- and 6 months follow up. Int J Ment Health Syst. 2012;6(1):1752-4458. https:// doi.org/10.1186/1752-4458-6-13

30. Abbo C, Okello E, Ekblad S, Waako P, Musisi S. Lay concepts of psychosis in Busoga, Eastern Uganda: A pilot study. World Cult Psychiatry Res Rev. 2008;3(3):132-145.

31. Abbo C, Ekblad S, Waako P, Okello E, Musisi S. The prevalence and severity of mental illnesses handled by traditional healers in two districts in Uganda. Afr Health Sci. 2009;1(9):S16-S22.

32. Abbo C. Profiles and outcome of traditional healing practices for severe mental illnesses in two districts of Eastern Uganda. Glob Health Action. 2011;4(1):7117. https://doi.org/10.3402/gha.v4i0.7117

33. Semrau M, Alem A, Abdulmalik J, et al. Developing capacity-building activities for mental health system strengthening in low- and middle-income countrie for service users and caregivers, service planners, and researchers. Epidemio Psychiatr Sci. 2018;27(1):11-21. https://doi.org/10.1017/S20457960170 00452

34. Petersen I, Marais D, Abdulmalik J, et al. Strengthening mental health system governance in six low- and middle-income countries in Africa and South Asia: Challenges, needs and potential strategies. Health Policy Plan. 2017;32(5): 699-709. https://doi.org/10.1093/heapol/czx014
35. Mugisha J, Abdulmalik J, Hanlon C, et al. Health systems context(s) for integrating mental health into primary health care in six Emerald countries: A situation analysis. Int J Ment Health Syst. 2017;11:7. https://doi.org/10.1186/s13033-016-0114-2

36. Humensky JL, Nossel I, Bello I, Dixon LB. Supported education and employment services for young people with early psychosis in OnTrackNY. J Ment Health Policy Econ. 2019;22(3):95-108.

37. Humensky JL, Turner LR, Dixon LB, et al. Personnel time required for supported employment and education services for individuals in a recent-onset psychosis treatment program. Early Interv Psychiatry. 2020;15(2):402-405. https://doi. org/10.1111/eip.12971

38. Guest PC. Insulin resistance in schizophrenia. Adv Exp Med Biol. 2019;1134:1-16 https://doi.org/10.1007/978-3-030-25650-0_1

39. Wubeshet YS, Mohammed OS, Desse TA. Prevalence and management practice of first generation antipsychotics induced side effects among schizophrenic patients at Amanuel Mental Specialized Hospital, Central Ethiopia: Crosssectional study. BMC psychiatry. 2019;19(1):32. https://doi.org/10.1186/ s12888-018-1999-x

40. Lally J, MacCabe JH. Antipsychotic medication in schizophrenia: A review. Br Med Bull. 2015;114(1):169-179. https://doi.org/10.1093/bmb/ldv017

41. Thungana $Y$, Zingela Z, Van Wyk S. First-episode psychosis and substance use in Nelson Mandela Bay: Findings from an acute mental health unit. S Afr J Psychiatry. 2019;25(0):1372. https://doi.org/10.4102/sajpsychiatry.v25i0.1372

42. Lo TL, Warden M, He Y, et al. Recommendations for the optimal care of patients with recent-onset psychosis in the Asia-Pacific region. Asia Pac Psychiatry. 2016;8(2):154-171. https://doi.org/10.1111/appy.12234

43. Kigozi FN, Kizza D, Nakku J, et al. Development of a district mental healthcare plan in Uganda. Br J Psychiatry. 2016;208(Suppl 56):s40-s46. https://doi.org/10.1192/ bjp.bp.114.153742 